\title{
Is There a Relationship Between Attention Deficit Hyperactivity Disorder and Manic Symptoms Among Children with Epilepy?
}

\author{
${ }^{1}$ Tülin Fidan, ${ }^{2}$ ilknur Ucuz, ${ }^{2}$ Hüseyin Tan \\ ${ }^{1}$ Eskişehir Osmangazi University Faculty of Medicine, Child and Adolescent Psychiatry \\ Department, Eskişehir \\ ${ }^{2}$ Ataturk University Faculty of Medicine, Child and Adolescent Psychiatry Department, Erzurum \\ *tulincps@ hotmail.com
}

ÖZET: Epilepsi, çocukluk çağı kronik hastalıklarından biridir. Epilepsisi olan çocuklarda bilişsel, davranışsal ve duygusal bozukluklar bildirilmiştir. Bu çalışmada epilepsi tanılı çocuklarda dikkat eksikliği hiperaktivite bozukluğu (DEHB), Yıkıcı Davranım Bozuklukları ve aynı zamamda mani belirtileri araştırılmıştır. Yöntem: 55 epilepsi tanılı çocuğa ve 55 sağlıklı kontrole Turgay DSMIV'e dayalı yıkıcı davranım bozukluğu ölçeği ve Young Mani Derecelendirme uygulanmıştır. Bulgular: Tüm çocukların \%54.5'i kız olup yaş ortalaması 12.38 \pm 2.64 idi. Bu çalışmada DEHB, Karşıt Olma Karşıt Gelme Bozukluğu (KOKGB), Davranım Bozukluğu(DB) sıklığı ve belirti şiddeti daha önce yapılan çalışmalara benzerdi ve mani oranı \%3.6 idi. KOKGB ve DB varlığı Young mani Değerlendirme Ölçeği-Ebeveyn Formu (YMDÖ-EF) değerlerinin etkilemektedir Tartı̧̧ma: Tüm epileptik hastaların psikiyatrik açıdan özellikle DEHB, KOKGB, DB ve maik belirtiler açısından değerlendirilmelidir.

ANAHTAR KELIMELER: Epilepsi, Nörodavranışsal Belirtiler, çocuk-ergen.

\begin{abstract}
Epilepsy is a chronic neurological disorder. Cognitive, behavioral and emotional impairment have been reported. In this study, we aimed to investigate the relationship between attention-deficit hyperactivity disorder (ADHD) and disruptive behavioral disorders (DBDs) as well as manic symptoms among children with epilepsy. Methods: Turgay DSM-IV Based Child and Adolescent Disruptive Behavioral Disorders Screening and Rating Scale (T-DSM-IV-S) and Young Mania Rating Scale - parent version (P-YMRS) were administered to 55 children with epilepsy and 55 healthy controls. Results: Of these, $54.5 \%$ were female and the mean age was $12.38 \pm 2.64$ years. In this study the rate and the symptom severity of ADHD, Oppositional Defiant Disorder (ODD) and Conduct Disorder (CD) were similar to previous reports and we found the rate of mania 3.6\%. Conduct Disorder (CD) and hyperactivity affected P-YMRS. Conclusion: All epileptic patients must be evaluated for psychiatric disorders especially for ADHD, DBSs and manic symptoms.
\end{abstract}

KEY WORDS: Neurobehavioral symptoms, child-adolescent.

\section{Giriş}

Epilepsy is a chronic neurological disorder affecting both sexes and all ages worldwide. This brain disorder is characterized by seizures with neurobiological, cognitive, psychological, and social consequences (1).
Children with epilepsy have a higher risk of behavioral, emotional, psychiatric, and social impairments compared with people with other medical conditions and healthy children (2). Common psychiatric problems associated with epilepsy include learning disabilities, poor academic achievements, attention-deficit hyperactivity disorders (ADHD), anxiety, depression, bipolar disorders, psychosocial 
imparments, low self-esteem, autistic spectrum disorders, psychosis, and agressive behaviors $(3,4,5)$.

Attention deficit/ hyperactivity disorder (ADHD) is characterized by severe, persistent, and early appearing symptoms of inattention, hyperactivity, and impulsivity (7).The prevalence of ADHD among children with epilepsy, estimated at between $12 \%$ and $39 \%$, is much higher than in the general population (6).In a typical population, half of the clinical samples with ADHD have comorbidity with oppositional-defiant disorders (ODD) or conduct disorders (CD). $\mathrm{CD}$ and ODD are known as disruptive behavioral disorders (DBDs) (7).

Conduct disorder constitutes a constellation of antisocial and aggresive behaviours that may become prominent in early childhood and persist through adolescence even in to adulthood and oppositional disorder is characterised with persistent patterns of resistant and negativistic behaviour in children (8).Irritability, impulsivity, hyperactivity, and distractibility are very frequent and not specific for mania (9).Elation, grandiosity, racing thoughts, decreased need for sleep and hypersexuality are common in bipolar disorder $(10,11)$.

In recent years, the most diagnostically challenging and controversial disorders cooccurring with ADHD are bipolar disorders (BPD). Irritability, impulsivity, hyperactivity, and distractibility are very frequent and not specific for mania (9).Elation, grandiosity, racing thoughts, decreased need for sleep and hypersexuality are common in bipolar disorder (10,11).ADHDs and BPDs show comorbidity, which decreases as the population under examination ages (12).In pediatric bipolar disorders, comorbidity with ADHD is especially high: An estimated $85 \%$ of children with bipolar disorders also have ADHD and up to $22 \%$ of children with ADHD have bipolar disorders in a typical population (13).

Several studies note significant comorbidity of ADHD, ODD,CD, mood, and anxiety disorders or psychotic disorders and epilepsy; however, studies using structured psychiatric interviews have not described bipolar disorders and/or manic symptoms in children with epilepsy $(2,14,15)$.

In this study, we investigated the manic symptoms and the relationship between ADHD, as well as ODD and CD among children with epilepsy.

\section{Materials and Methods}

This study was carried out in the Pediatric Neurology Outpatient Clinic at the Ataturk University Faculty of Medicine in Erzurum, Turkey, among children with long-standing epilepsy of more than one year. Fifty-five children, ages 7-17, with epilepsy and sex and age matched 55 healthy children without epilepsy in control group were included in the study. The control group was comprised randomly from the healthy students of two different public schools. The participants who were under seven years old, had metabolic and genetic diseases, and underlying neurologic diseases, mental retardation and any previous psychiatric history were excluded from the study.

Parents were interviewed by the researchers and they completed the Child Disruptive Behavioral Screening and Rating Scale related to DSM IV (T-DSM-IV-S) and the Young Mania Rating Scale-parent version (PYMRS). The parents or guardians of all participants were informed about the aim of the study by the researchers and informed consent was obtained from all parents or guardians.

\section{Instruments}

Turgay DSM-IV-Based Child and Adolescent Disruptive Behavioral Disorders Screening and Rating Scale (T-DSM-IV-S)

The T-DSM-IV-S was developed by Turgay and translated and adapted into Turkish by Ercan et al. (16). The T-DSM-IV-S is based on the DSM-IV diagnostic criteria and assesses hyperactivity/impulsivity, inattention, ODD, and CD. The symptoms were scored by assigning a severity estimate for each symptom on a four-point Likert scale $(0=$ not at all, $1=$ somewhat, $2=$ quite a bit, and $3=$ very much). Several studies from different cultures have shown the validity of this scale 
for diagnosing ADHD by parents and teachers (17).

\section{Young Mania Rating Scale: Parent Version (P-YMRS)}

YMRS is an 11-item scale used to assess the severity of mania in patients with bipolar disorders. The items assessed the following areas: elevated mood, increased motor activity/energy, sexual interest, sleep, irritability, speech (rate and amount), language (thought disorders), thought content, disruptive-aggressive behavior, and appearance and insight (18).A parent version of the YMRS (P-YMRS) was developed to assess bipolar disorders in youths based on informant ratings (19).The P-YMRS rating form has 11 multiple-choice items that are scored from 0 to 8 . Parents rate their children's manic symptoms on five explicitly defined grades of severity, with item scores ranging from 0 to 4 (and items 5, 6, and 8 from $0-8$ to weight items for clinical importance). The P-YMRS yields a total score that can range from 0 to 56, with higher scores representing greater psychopathology. The scale was translated into Turkish and shown to discriminate bipolar disorders in a clinical sample of Turkish children. Ratings were based on the reported presence of the symptoms over the past two weeks $(20,21)$.The P-YMRS significantly discriminated bipolar from non-bipolar cases in youths ages 5 to 18 in academic and community mental health settings (22).

The literature did not reveal any studies that examined the psychometric properties of $\mathrm{P}$ YMRS among children with epilepsy. Thus, no cutoff point for P-YMRS could be determined. In our study population, we used the cut-off scores of 17 and 27 on total PYMRS and these were defined as efficient and specific, respectively, for BPD children (23). We defined the mania group as having PYMRS scores higher than or equal to 27, the probable-mania group as having P-YMRS scores higher than or equal to17 but lower than 27, and the normal group as having PYMRS scores lower than 17.

\section{Epilepsy-Related Variables}

The medical epilepsy-related variables were categorized as follows: seizure type (generalized or partial), age at first seizure, seizure frequency (seizure free during the last six months or with seizures in the last six months), and anticonvulsive therapy at the time of assessment (monotherapy, polytherapy, or none). The epilepsy syndromes of the patients were classified according to the International Classification of Epilepsies, Epileptic Syndromes, and Related Seizure Disorders (24).

\section{Sociodemographic Form}

This form contains the sociodemographic features of the children and their families.

\section{Statistical Analysis}

The SPSS-15.0 statistical package program was used for the statistical analyses. The categorical variables were presented as percentages and the continuous variables were presented as means \pm standard deviation. We used the one-sample Kolmogorov Smirnov test to assess the normal distribution of the ADHD, ODD, CD, PYMRS scores. We searched and compared the manic symptoms (on the P-YMRS) and ADHD scores between the study groups by using student t-tests. We also assessed correlations between P-YMRS and ADHD scores by Pearson's product moment correlation. A value of $\mathrm{p}<0.05$ was considered statistically significant.

The relationships between inattention, hyperactivity, ODD, CD, time period having epilepsy, and P-YMRS scores were analyzed by multiple linear regressions (i.e., the stepwise method). The independent variables for the reference category were inattention, hyperactivity, ODD, CD, and time period having epilepsy.

\section{Results}

A total of 55 children with epilepsy were assessed in this study. Of these, $30(54.5 \%)$ were girls and $25(45.5 \%)$ were boys, and their mean age was $12.7 \pm 2.6$ years. The number of children with epilepsy according to an age group of $21(38.2 \%)$ between the ages of 7 and 11 years old and $34(61.8 \%)$ between the ages of 12 to 17 . All of these children were going to secondary and high schools (Table 1). 
Table 1

Characteristics of the children with epilepsy

\begin{tabular}{|c|c|c|}
\hline \multirow{2}{*}{ Değişkenler } & \multicolumn{2}{|c|}{ Children with epilepsy } \\
\hline & $n$ & $\%$ \\
\hline \multicolumn{3}{|l|}{ Gender } \\
\hline Boys & 25 & $45.5 \%$ \\
\hline Girls & 30 & $54.5 \%$ \\
\hline \multicolumn{3}{|l|}{ Education Level (Mother/Father) } \\
\hline Uneducated & $11 / 2$ & $20.0 \% / 3.6 \%$ \\
\hline Primary- Secondary school & $38 / 27$ & $69.1 \% / 49.1 \%$ \\
\hline High school & $6 / 17$ & $10.9 \% / 30.9 \%$ \\
\hline University & $0 / 9$ & $0 / 16.4$ \\
\hline \multicolumn{3}{|l|}{ Occupation (Mother/Father) } \\
\hline Housewife/unemployed & $54 / 4$ & $98.2 \% / 2.4 \%$ \\
\hline Self-employed & $0 / 21$ & $0 / 38.2 \%$ \\
\hline Government employee & $1 / 16$ & $1.8 \% / 29.1 \%$ \\
\hline Worker & $0 / 12$ & $0 / 21.8 \%$ \\
\hline Retired Official & $0 / 2$ & $0 / 3.6 \%$ \\
\hline \multicolumn{3}{|l|}{ Age groups of Mother/Father } \\
\hline $20-40$ & $30 / 18$ & $54.5 \% / 32.7 \%$ \\
\hline$>40$ & $25 / 37$ & $45.5 \% / 67.3 \%$ \\
\hline \multicolumn{3}{|l|}{ ADHD } \\
\hline \multicolumn{3}{|l|}{ Inattention } \\
\hline Present & 4 & $7.3 \%$ \\
\hline Absent & 51 & $92.7 \%$ \\
\hline \multicolumn{3}{|l|}{ Hyperactivity } \\
\hline Present & 7 & $12.7 \%$ \\
\hline Absent & 48 & $87.3 \%$ \\
\hline \multicolumn{3}{|l|}{ ODD } \\
\hline Present & 9 & $16.4 \%$ \\
\hline Absent & 46 & $83.6 \%$ \\
\hline \multicolumn{3}{|l|}{$\mathrm{CD}$} \\
\hline Present & 5 & $9.1 \%$ \\
\hline Absent & 50 & $90.9 \%$ \\
\hline \multicolumn{3}{|l|}{ P-YMRS } \\
\hline $\begin{array}{r}<17 \\
17-26\end{array}$ & $\begin{array}{c}45 \\
8\end{array}$ & $\begin{array}{l}81.8 \% \\
14.5 \%\end{array}$ \\
\hline$\geq 27$ & 2 & $3.6 \%$ \\
\hline
\end{tabular}

According to T-DSM-IV-S, four (7.3\%) of the children with epilepsy had inattention, seven $(12.7 \%)$ had hyperactivity, nine $(16.4 \%)$ had ODD, andfive $(9.1 \%)$ had CD. In control group , two $(3.6 \%)$ of the children had inattention, four $(7.3 \%)$ had hyperactivity, seven (12.7\%) had ODD, two (3.6\%) had CD.

According to P-YMRS, 45 (81.8\%) children with epilepsy had scores of $<17,8$ (14.5\%) and scores between 17 and 26 , and only two (3.6\%) had scores of $\geq 27$.

No statistical differences in the frequency of inattention were noted: $\left(\chi^{2}=0.71, \mathrm{p}=0.40\right)$, hyperactivity $\quad\left(\chi^{2}=0.91, \quad \mathrm{p}=0.34\right), \quad$ ODD $\left(\chi^{2}=0.01, \mathrm{p}=1\right), \mathrm{CD}\left(\chi^{2}=2.08, \mathrm{p}=0.35\right)$ and mania/probable mania was $\left(\chi^{2}=0.27, p=0.87\right)$ between children with epilepsy and healthy controls.

The mean of the age at the first seizure was $8.1 \pm 3.7$ years and the mean of having epilepsy was $49.1 \pm 36.2$ months. Among the children with epilepsy, $87.3 \%$ had generalized seizures and $12.7 \%$ were having partial epileptic seizures; $41.8 \%$ were having seizures within six months; and $76.1 \%$ were using monotherapy (52.7\% were using valproic acid and $23.6 \%$ were using carbamazepine), and $18.2 \%$ were using polytherapy (Table 2 ). 
Table 2

The characteristics of children with epilepsy

\begin{tabular}{lccc}
\hline Değişkenler & & Epileptic patients \\
& & $n$ & $\%$ \\
\hline Epilepsy type & Generalised & 48 & $87.3 \%$ \\
& Partial & 7 & $12.7 \%$ \\
Having seizure during the last 6 months & & \\
& Being & 23 & $41.8 \%$ \\
anticonvulsive therapy* & Absent & 32 & $58.2 \%$ \\
& & & \\
& monotherapy & 42 & $76.1 \%$ \\
& polytherapy & 10 & $18.2 \%$ \\
& none & 3 & $5.7 \%$
\end{tabular}

The mean score of inattention was $6.9 \pm 4.9$, hyperactivity was $7 \pm 5.9$, ODD was $6.3 \pm 3.8$, $\mathrm{CD}$ was $1.5 \pm 2.6$, and P-YMRS was $9.4 \pm 7.0$ (Table 3). There was no statistically significant difference in the mean scores of Inattention, Hyperactivity, $\mathrm{ODD}, \mathrm{CD}$, and $\mathrm{P}$ YMRS between children with epilepsy and the healthy controls ( $p>0.05$ ).

\section{Table 3}

The mean scores of Inattention, Hyperactivity, ODD, CD, and P-YMRS in epileptic children

\begin{tabular}{lccc}
\hline Değişkenler & $\begin{array}{c}\text { Epileptic children } \\
\text { mean } \pm \text { SD }\end{array}$ & $\begin{array}{c}\text { Healthy Controls } \\
\text { mean } \pm \text { SD }\end{array}$ & $\mathrm{p}$ \\
\hline Inattention & $6.9 \pm 4.9$ & $5.5 \pm 5.1$ & 0.14 \\
Hyperactivity & $7.0 \pm 5.9$ & $6.3 \pm 6.0$ & 0.55 \\
ODD & $6.3 \pm 3.8$ & $5.9 \pm 5.4$ & 0.67 \\
CD & $1.5 \pm 2.6$ & $1.5 \pm 2.3$ & 0.96 \\
P-YMRS & $9.4 \pm 7.0$ & $10.2 \pm 8.1$ & 0.55 \\
\hline
\end{tabular}

We were unable to find a statistically significant difference in mean scores of $\mathrm{P}$ YMRS and age or gender $(\mathrm{p}>0.05)$, but we found a statistically significant difference between the time period after an epileptic seizure and the mean scores of P-YMRS $(\mathrm{t}=$ $1.98, \mathrm{p}<0.05)($ Table 4).

\section{Table 4}

The mean scores of P-YMRS according to age, gender, and Disruptive Behavioral Disorders $(D B S s)$ in children with epilepsy

\begin{tabular}{|c|c|c|}
\hline \multirow{2}{*}{ Değişkenler } & \multicolumn{2}{|c|}{ Epileptic patients } \\
\hline & $n$ & $\%$ \\
\hline \multicolumn{3}{|l|}{ Age } \\
\hline $7-11$ & $8.2 \pm 6.3$ & $8.2 \pm 6.3$ \\
\hline $12-17$ & $10.2 \pm 7.1$ & $10.2 \pm 7.1$ \\
\hline \multicolumn{3}{|l|}{ Gender } \\
\hline Male & $10.6 \pm 7.9$ & $10.6 \pm 7.9$ \\
\hline Female & $8.4 \pm 6.1$ & $8.4 \pm 6.1$ \\
\hline \multicolumn{3}{|l|}{ The time period after an epileptic seizure } \\
\hline $0-6$ months & $11.6 \pm 8.4^{*}$ & $11.6 \pm 8.4^{*}$ \\
\hline$>7$ & $7.8 \pm 5.4^{*}$ & $7.8 \pm 5.4^{*}$ \\
\hline
\end{tabular}


We found a positive correlation between the mean scores of P-YMRS and the mean scores of inattention, hyperactivity, ODD, and $\mathrm{CD}$ among children with epilepsy ( $\mathrm{r}=0.45, \mathrm{p}<0.01$; $\mathrm{r}=0.53 \mathrm{p}<0.01 ; \mathrm{r}=0.56, \mathrm{p}<0.01)$, respectively (Table 5).

Table 5

Pearson's correlation coefficients between P-YMRS scores and ADHD-DBSs scores

\begin{tabular}{l|ccccc}
\hline & & & & & \\
& P-YMRS & .Inattention & Hyperactivity & ODD & CD \\
\hline P-YMRS & 1 & & & & \\
Inattention & $.446^{* *}$ & 1 & & & \\
Hyperactivity & $.525^{* *}$ & $.653^{* * *}$ & 1 & & \\
ODD & $.494^{* *}$ & $.651^{* *}$ & $0.649^{*}$ & 1 & 1 \\
CD & $.555^{* *}$ & $.424^{* *}$ & $0.378^{*}$ & $0.648^{*}$ & 1 \\
\end{tabular}

For children with epilepsy, we conducted a multiple linear regression analysis by the stepwise method in order to examine the relation between inattention, hyperactivity,
ODD, CD, time period having epilepsy, and P-YMRS scores. We found that $\mathrm{CD}$ and hyperactivity affected P-YMRS scores $(\mathrm{p}<0.001, \mathrm{p}<0.001)($ Table 6$)$.

Table 6

Factors related to P-YMRS scores in children with epilepsy

\begin{tabular}{lccccc}
\hline Variables & $\beta$ & $\mathbf{t}$ & $\mathbf{p}$ & $\mathbf{R}$ & $\mathbf{R}^{2}$ \\
\hline Conduct Disorder & .555 & 4.853 & $\mathrm{p}<0.001$ & .555 & .308 \\
Conduct Disorder & .419 & 3.720 & $\mathrm{p}<0.001$ & .654 & .428 \\
Hyperactivity & .372 & 3.300 & $\mathrm{P}=0.002$ & & \\
\hline
\end{tabular}

Dependent variable: P-YMRS scores

In this equation, $\mathrm{R}^{2}$ was 0.42 for the P-YMRS scores. The conduct disorder and hyperactivity were found to account for approximately $42 \%$ of the variance on $\mathrm{P}$ YMRS scores in this sample of individuals with epilepsy.

\section{Discussion}

Estimates of bipolar disorders in the epileptic population are not known clearly. In the present study, we assessed children with epilepsy using P-YMRS and T-DSM-IV-S. We found that there was no difference in the frequency and symptom severity of mania/probable mania, inattention, hyperactivity, ODD, and CD among children with epilepsy and healthy controls. In the literature, studies using structured psychiatric interviews have not described for bipolar disorders and manic symptoms in children with epilepsy (7).It is unclear whether this reflected a low base rate of this disorder in pediatric epilepsy, the mood stabilizing effect of antiepileptics, the type of diagnostic instruments, or the diagnostic practices of child psychiatrists who worked with this children with epilepsy. The low rates of externalizing behaviors but high rates of internalizing behaviors in CBCL studies of children with epilepsy implied that bipolar disorder might be rare in pediatric epilepsy (2).

In the present study, among children with epilepsy, we found the rate of mania as $3.6 \%$ and the rate of probable mania as $14.5 \%$ based on P-YMRS scores. To the best of our knowledge, there is no previous sufficient data about manic symptoms in children with epilepsy. However, in clinical populations, among children, the prevalence of BPD has been reported as between $0.6 \%$ and $15 \%$, depending on the setting, the referral source and the methodology used to ascertain BPD (25). 
In our previous study, we found that the rate of probable mania was $7.2 \%$ and mania was found for $1.8 \%$, according to P-YMRS among children with mental retardation with an unknown etiology (26). Our findings showed a similar rate of bipolar disorder among normally developed children, but this was two-fold higher than the mentally retarded population.

The mean scores of P-YMRS showed no differences according to gender and age. In the literature, gender variations were not consistent for children with epilepsy. While some studies found that boys with epilepsy show more problematic psychological adjustment than girls with epilepsy, some studies have shown no gender differences (3).

In this study, we found that the children having epileptic seizure in the past six months were having higher P-YMRS scores than their counterparts. In the literature, bipolar disorder symptoms have been more often reported as postictal phenomena in children with epilepsy (27).The higher mean scores of P-YMRS in children having epileptic seizures during last six months might be as a result of postictal behavioral changes (PBCs) determined as mood changes, psychosis, and aggression after and epileptic seizures (28).

Ito (2010) suggested YMRS for the evaluation of mania in patients with epilepsy as we used P-YMRS in our study and considered that scores obtained directly may not reflect the severity of the psychopathology of the patient. Diagnosis of psychiatric symptoms on the basis of scores sometimes leads to misunderstanding of the patient. The results should be compared between different evaluation periods or patients should be compared with controls as we did in our study (28). In this study, the frequency and symptom severity of mania according to PYMRS among children with epilepsy showed no difference from the healthy controls. Nishida et al. found that mania in epileptic patients was different from mania in bipolar patients, that the severity of manic symptoms was lesser in patients with epilepsy and patients with epilepsy were having behavioral deviants like dependent-childish behavior (29).
In the present study, we found the rate of ADHD in children with epilepsy was $18.2 \%$, in control group was $9.1 \%$. There was a difference in the frequency of ADHD between epileptic and healthy controls but we were unable to find a statistically significance. Gonzalez-Heydrich et al. 2007 also found that comorbidity in ADHD with epilepsy is similar to that of ADHD without epilepsy reported in the literature. These preliminary data argued that the pathophysiology of ADHD has common components in both populations (30).The findings of this study are different to those of the some previous studies. Kaufman et al. 2009 stated that at least $20 \%$ of children with epilepsy have clinical attention-deficit hyperactivity disorder (ADHD) compared to $3 \%$ to $7 \%$ of the general pediatric population (31).Dunn et al. 2003 also reported the symptom complex of ADHD in 38\% of 175 children diagnosed with epilepsy at least 6 months previously (32).

In the present study, we found that P-YMRS was significantly correlated with all ADHD and DBDs scores. The highest correlations of P-YMRS were for $\mathrm{CD}(\mathrm{r}=0.55)$, hyperactivity $(\mathrm{r}=0.52)$, ODD $(\mathrm{r}=0.49)$, and inattention $(r=0.44)$ scores on the T-DSM-IV-S. We also examine the correlations of each item of PYMRS and ADHD and DBDs scores. The items of P-YMRS insight were found to be correlated with hyperactivity and the items of P-YMRS disruptive-aggressive behavior were found to be correlated with ODD. There was no previous and sufficient data to establish a relationship between ADHD and manic symptoms in children with epilepsy. To the best of our knowledge, this study is the first to investigate the relationship between ADHD, ODD, and CD and manic symptoms in children with epilepsy.

In children with epilepsy, multiple linear regression analysis was used to examine the effects of ADHD and DBDs on P-YMRS. We found that having $C D$ and hyperactivity affected the scores of P-YMRS. We can say that behavioral problems and hyperactivity might have been the predictors of manic symptoms among children with epilepsy. The key elements of bipolar spectrum disorders, such as mood lability, impulsivity, and rage outbursts in a pediatric epilepsy population have also been described in epilepsy syndromes $(33,34)$.This overlap has 
stimulated discussion regarding common biologic underpinning to bipolar disorder and epilepsy. The kindling model of epileptogenesis or other neurochemical models have produced intriguing theories as to the molecular pathophysiology of both illnesses (35).

In this study most of the children with epilepsy were taking anticonvulsants but none of the children with epilepsy were taking psychiatric medication.Anticonvulsants might have been a counfounding effect on the scores of PYMRS that our findings showed a similar rate of bipolar disorder among normally developed children. It is known that anticonvulsant medicines were unique in that they often served as effective first-line treatments for epilepsy and bipolar spectrum disorders (36) and reducing the hyperexcitability of neurons may have benefits in treating bipolar spectrum and seizure disorders (37).

As with all research, this study also has limitations and strengths. We used the cut-off scores of the P-YMRS validated for the normally devolopment children and adolescents and thus may diminish its usefulness as a quantitative measure for mania. The validity of P-YMRS was needed for children with epilepsy. Our study was a case-control study significant results are unlikely to be just statistical chance even though multiple analyses were used. We also excluded the children having psychiatric history and medication to avoid possible confounding effects.

\section{Conclusion}

In conclusion, there was a strong relationship between epilepsy and bipolar disorders. The frequency and severity of ADHD and disruptive behaviors, as well as manic symptoms, were not different among children with epilepsy compared with the healthy controls. CD and hyperactivity affected the PYMRS in children with epilepsy. Further investigations will be necessary to determine the rates and correlates of manic symptoms in epileptic patients.

\section{REFERENCES}

1. World Health Organization. (2006). Neurological disorders: public health challenges. Switzerland: World Health Organization.

2. Rodenburg, R. Meijer, A.M. Dekovi, M. Aldenkamp, A.P. (2005). Family factors and psychopathology in children with epilepsy: a literature review. Epilepsy Behav. 6:488-503.

3. Otero, S. (2009). Psychopathology and psychological adjustment in children and adolescents with epilepsy. World J Pediatr.5(1):1217.

4. Salpekar, J.A. Dunn, D.W. (2007). Psychiatric and Psychosocial Consequences of Pediatric. Semin Pediatr Neurol. 14(4):181-188.

5. Plioplys, S. Dunn, D.W. Caplan, R. (2007). 10Year Research Update Review: Psychiatric Problems in Children With Epilepsy. J. Am. Acad. Child Adolesc. Psychiatry. 46(11):1389-1402.

6. American Academy of Pediatrics. (2000). Subcommittee on Attention- Deficit/Hyperactivity D, Committee on Quality I. Clinical practice guideline: diagnosis and evaluation of the child with attention-deficit/ hyperactivity disorder. Pediatrics.105:1158-1170.

7. Spetie, L. Arnold, E.L. (2007). Attention Deficit Hyperactivity Syndrome. In: Martin A, Volkmar FR, editors. Lewis's Child and Adolescent
Psychiatry. A Comprehensive Textbook. Phiadelphia: Lippincott Williams \& Wilkins. p. 430-454.

8. Rey, J.M. Walter, G. Soutullo, C.A. (2007). Oppositional Defiant and Conduct Disorders In: Martin A, Volkmar FR, editors. Lewis's Child and Adolescent Psychiatry. A Comprehensive Textbook. Phiadelphia: Lippincott Williams \& Wilkins. p. 454- 467.

9. Mick, E. Spencer, T. Wozniak, J. (2005). Heterogeneity of irritability in attention deficit/hyperactivity disorder subjects with and without mood disorders. Biol Psychiatry. 58: 576-582.

10. Geller, B. Zimerman, B. Williams, M. Delbello, M.P. et al. (2002). Phenomenology of prepubertal and early adolescent bipolar disorder: examples of elated mood, grandiose behaviors, decreased need for sleep, racing thoughts and hypersexuality. J Child Adolesc Psychopharmacol; 12(1):3-9.

11. Pavuluri, M.N. Birmaher, B. Naylor, M.W. (2005). Pediatric bipolar disorder: A review of the past 10 years. J Am Acad Child Adolesc Psychiatry. 44(9):846-871.

12. Tamam, L. Karakus, G. Ozpoyraz, N. (2008). Comorbidity of adult attention-deficit hyperactivity disorder and bipolar disorder: prevalence and 
clinical correlates. Eur Arch Psychiatry Clin Neurosci. 258:385-393.

13. Singh, M.K. DelBello, M.P. Kowatch, R.A. Strakowski, S.M. (2006). occurrence of bipolar and attention-deficit hyperactivity disorders in children. Bipolar Disord. 8: 710-720.

14. Caplan, R. Siddarth, P. Gurbani, S. et al. (2005). Depression and anxiety disorders in pediatric epilepsy. Epilepsia. 46: 720-730.

15. Dunn, D.W. Austin, J.K. Perkins, S.M. (2009). Prevalence of psychopathology in childhood epilepsy: categorical and dimensional measures. Dev Med Child Neurol. 51(5): 364-372.

16. Ercan, E.S. Amado, S. Somer, O. Çıkoğlu, S. (2001). A work for developing a test for Attention Deficit Hyperactivity Disorder and Disruptive Behaviours Disorders. Turkish Journal of Child and Adolescent Mental Health. 8:132- 144.

17. Magnusson, P. Smari, J. Greatasdottir, H. Prandardottir, H. (1999). Attention deficit/ hyperactivity symptoms in Icelandic Schoolchildren: assessment with the attention deficit/hyperactivity rating scale. Scand J Psychol. 40:301-306.

18. Young, R.C. Biggs, J.T. Ziegler, V.E. Meyer, D.A. (1978). A rating scale for mania: reliability, validity and sensitivity. British Journal of Psychiatry. 133:429-431.

19. Gracious, B.L. Youngstrom, E.A. Findling, R.L. Calabrese, J.R. (2002). Discriminative Validity of a Parent Version of the Young Mania Rating Scale. J Am Acad Child Adolesc Psychiatry. 41(11):13501359.

20. Diler, R.S. Uguz, S. Seydaoglu, G. Erol, N. Avci, A. (2007). Differentiating bipolar disorder in Turkish prepubertal children with attention-deficit hyperactivity disorder. Bipolar Disord. 9: 243-251.

21. Youngstrom, E.A. Findling, R.L. Calabrese, J.R. (2004). Effects of adolescent manic symptoms on agreement between youth, parent, and teacher ratings of behavior problems. J Affect Disord. 82(Suppl.1): 5-16.

22. Youngstrom, E. Youngstrom, J.K. Starr, M. (2005). Bipolar diagnoses in community mental health: Achenbach Child Behavior Checklist profiles and patterns of comorbidity. Biol Psychiatry. 58: 562568.

23. Youngstrom, E.A. Gracious, B.L. Danielson, C.K. Findling, R.L. Calabrese, J. (2003). Toward an integration of parent and clinician report on the Young Mania Rating Scale. J Affect Disord.77: 179-190.

24. International Classification of Epilepsies, (1989). Epileptic Syndromes and Related Seizure Disorders. Epilepsia. 30: 389-399.

25. Birmaher, B. Axelson, D. Pavuluri, M. (2007). Bipolar Disorder. In: Andres M, Volkmar FR, editors. Lewis's Child and Adolescent Psychiatry: A Comprehensive Textbook. Philadelphia: Lippincott Williams \& Wilkins . p. 513- 528.

26. Fidan, T. Oral, M. Koçak, K. Kırpınar, I. (2011). Is there a relationship between attention deficit/hyperactivity disorder and manic symptoms among children with mental retardation of unknown etiology? Compr Psychiatry. NovDec.52(6):644-49.
27. Kudo, T. Ishida, S. Kubota, H. et al. (2001). Manic episode in epilepsy and bipolar I disorder: A comparative analysis of 13 patients. Epilepsia. 42:1036-1042.

28. Ito, M. (2010). Neuropsychiatric evaluations of postictal behavioral changes. Epilepsy Behav. 19:134-137.

29. Nishida, T. Kudo, T. Nakamura, F. et al. (2005). Postictal mania associated with frontal lobe epilepsy. Epilepsy Behav. 6:102-110.

30. Gonzalez-Heydrich, J. Dodds, A. Whitney, J. MacMillan, C. Deborah Waber, Stephen, V. Faraone, Katrina Boyer, Christine Mrakotsky, David DeMaso, Blaise Bourgeois, and Joseph Biederman. (2007). Psychiatric disorders and behavioral characteristics of pediatric patients with epılepsy and ADHD. Epilepsy Behav. 10(3): 384388.

31. Kaufmann, R. Goldberg-Stern, H. Shuper, A. (2009). Attention-Deficit Disorders and Epilepsy in Childhood: Incidence, Causative Relations and TreatmentPossibilities. J Child Neurol. 24(6):727733

32. Dunn, D.W. Austin, J.K. Harezlak, J. Ambrosius, W.T. (2003). ADHD and epilepsy in childhood. Dev Med Child Neurol. 45:50-54.

33. Besag, F.M. (2004). Behavioral aspects of pediatric epilepsy syndromes. Epilepsy Behav. (suppl 1) 5:313.

34. Kanner, A.M. (2004). Recognition of the various expressions of anxiety, psychosis, and aggression in epilepsy. Epilepsia. (suppl 2) 45:22-27.

35. Amann, B. Grunze, H. (2005). Neurochemical underpinnings in bipolar disorder and epilepsy. Epilepsia. (suppl 4) 46:26-30.

36. Post, R.M. Denicoff, K.D. Frye, M.A. et al. (1998). A history of the use of anticonvulsants as mood stabilizers in the last two decades of the 20th century. Neuropsychobiology. 38:152- 166.

37. Salpekar, J.A. Conry, J.A. Doss, W. et al. (2006). Clinical experience with anticonvulsant medication in pediatric epilepsy and comorbid bipolar spectrum disorder. Epilepsy Behav. 9:327-334. 